\title{
Effects on Wound Healing of Human-Induced Pluripotent Stem Cell-Derived Cells Similar to Endothelial Colony-Forming Cells
}

\author{
Sang Hun Kim $\mathbb{D}^{1}$, Jeoung Hyun Nam $\mathbb{D}^{1}$, Man Ryul Lee $\mathbb{B}^{2}$, Yongsung Hwang $\mathbb{D}^{2}$, Eun Soo Park $\mathbb{D}^{1}$ \\ ${ }^{1}$ Department of Plastic and Reconstructive Surgery, Soonchunhyang University Bucheon Hospital, Bucheon; ${ }^{2}$ Soonchunhyang Institute of Medi-bio Science \\ (SIMS), Soonchunhyang University, Cheonan, Korea
}

\begin{abstract}
Background: Human-induced pluripotent stem cells (hiPSCs) complement the disadvantages of conventional embryonic stem cells and adult stem cells, and have the advantages of simplicity of production and pluripotency. Some recent studies have applied hiPSC in cell therapy. Methods: In this study, we examined the effect of cells similar to cord blood endothelial colony-forming cells (CB-ECFCs), differentiated from induced pluripotent stem cells, on angiogenesis and granulation tissue formation in the proliferative phase of wound healing. For cell transfer, we used methacrylated gelatin (GeIMA)-co-poly(styrene sulfonate) (PSS) cryogel, which has better bioactivity than conventional hydrogels and excellent mechanical properties and swelling capacity. Two full-thickness skin defects, $0.8 \mathrm{~cm}$ in diameter, were made in each of our 12 experimental mice. Wound splinting models were used to prevent contraction of the wounds. In each of the experimental animals, $5 \times 10^{5}$ cells were applied with GelMA-co-PSS cryogel in one of the two wounds, while only a culture medium with cryogel was applied to the other wound.

Results: Wound reduction rates in the experimental side showed increases compared to the control side in 3 days, but there was no statistical significance. The histological score was significantly increased $(P<0.05)$, and histologic examination showed that angiogenesis and granulation formation were also increased in the experiment side.

Conclusion: In conclusion, CB-ECFCs-like cells differentiated from hiPSCs were effective in promoting formation of angiogenesis and granulation tissue in a mouse wound healing model.
\end{abstract}

Keywords: Cryogels; Endothelial cells; Induced pluripotent stem cells; Splints; Wound healing

\section{Introduction}

Wound healing is caused by intercellular action and complex mechanisms of cytokines and extracellular matrix. Many studies using stem cell therapy to explore the mechanism and promotion of wound treatment are underway. However, research using embryonic stem cells (ESCs) has been in short supply because of ethical concerns. Meanwhile, use of adult stem cells is allowed, but they are obtained only in very small numbers, and their ability to differentiate into specific cell types is limited compared to ESCs.

In 2006, Yamanaka [1] found induced pluripotent stem cells (iPSCs) by reprogramming somatic cells, delivering a simple technology that allows for high diversity. The cells are a recent subject of regenerative medicine and cell therapy research [2]. The advantages of the iPSC have attracted researchers to experiment for wound healing effects, but there are concerns of cancer development. More recent studies have focused on the induction of direct differentiation of stem cells into a cell lineage associated with wound healing [3].

\section{Original Article}

Received: November 29, 2019

Revised: February 8, 2019

Accepted: February 8, 2019

\section{Corresponding author:}

Eun Soo Park, M.D., Ph.D.

Department of Plastic and Reconstructive Surgery, Soonchunhyang University Bucheon Hospital, 170 Jomaru-ro, Wonmi-gu, Bucheon 14584 , Korea

Tel: +82-32-621-5319

Fax: +82-32-621-5016

E-mail: peunsoo@schmc.ac.kr

This is an Open Access article distributed under the terms of the Creative Commons Attribution Non-Commercial License (https://creativecommons.org/licenses/by-nc/4.0/) which permits unrestricted non-commercial use, distribution, and reproduction in any medium, provided the original work is properly cited.

(c) 2020 Korean Wound Management Society 
This study aims to investigate, using a wound healing splint model [4], whether cells transformed from human iPSCs (hiPSCs) to cells similar to endothelial colony-forming cells (ECFCs) of the umbilical cord blood (CB) have strong self-replication and vascularization abilities, and can promote wound healing, especially during the proliferative phase.

\section{Methods}

\section{Production of CB-ECFCs Human iPSCs}

Fibroblast-derived iPSCs (DF19-9-11T) [5] were obtained from the WiCell Research Institute (Madison, WI, USA). hiPSCs were cultured in a $10 \mathrm{~cm}^{2}$ tissue culture dish with mTeSR 1 complete media (Stem Cell Technologies, Vancouver, BC, Canada) at $37^{\circ} \mathrm{C}$ and $95 \%$ air $/ 5 \% \mathrm{CO}_{2}$. On day $5,4-5 \mathrm{~mL}$ of Dispase ( $2 \mathrm{mg} / \mathrm{mL}$; Gibco, Grand Island, NY, USA) was added and the cells were incubated at $37^{\circ} \mathrm{C}$ for $3-5$ minutes. Afterwards the enzyme was washed three times with DMEM-F12 (Gibco) to remove remaining enzymes. The remaining cell clusters were harvested and centrifuged at $300 \mathrm{~g}$ for 5 minutes. After separating the supernatant, the pellet was resuspended in mTeSR1 complete medium. A $10-\mathrm{cm}^{2}$ tissue culture dish was preliminarily coated with Matrigel for 30 minutes, after which $7 \mathrm{~mL}$ of mTeSR1 medium was added. Cell clusters contained in the mTeSR1 medium were then added to the dish.

\section{Differentiation into ECFCS}

After incubating for 2 days, activin A (10 ng/mL), fibroblast growth factors-2 (FGF-2; Stemgent, Cambridge, MA, USA), vascular endothelial growth factor $\left(\mathrm{VEGF}_{165}\right.$; R\&D Systems, Minneapolis, MN, USA), and bone morphogenic proteins 4 (BMP4; R\&D Systems) (10 ng/mL) were added and incubated for 24 hours. Endothelial cells were induced by adding $8 \mathrm{~mL}$ of Stemline II complete medium (Sigma-Aldrich, St. Louis, MO, USA) containing FGF-2, $\mathrm{VEGF}_{165}$, and BMP4 after removing the activin A medium. On day 9, the cells were changed to 10 $\mathrm{mL}$ Stemline II differentiation media. After 12 days of differentiation, adhered cells were collected using TrypLE (Gibco) and a single-cell suspension was prepared in an endothelial growth medium-2 (EGM-2; Lonza, Walkersville, MD, USA). CD31+NPR-1+ sorted cells were attached to a $75-\mathrm{cm}^{2}$ culture flask using supplements (10\% fetal bovine serum, $0.2 \%$ hydrocortisone, $2 \%$ human recombinant FGF- $\beta$, 0.5\% VEGF, $0.5 \%$ insulin-like growth factor, $0.5 \%$ ascorbic acid, $0.5 \%$ human epidermal growth factor, $0.5 \%$ gentamicin/amphotericin-B, and $0.5 \%$ heparin) containing EGM-2. The cells were incubated at $37^{\circ} \mathrm{C}$ in $95 \%$ air $/ 5 \% \mathrm{CO}_{2}$. To identify ECFC colonies we used morphological identification [6]. ECFCs generally satisfy the following morphological criteria: (1) initial ECFC clusters consist of trigonal and polygonal cells; (2) early ECFC colonies form after 7-8 days of culture and the typical ECFC colonies appear after 10 days of culture; (3) ECFC colonies display a typical cobblestone-like morphology under high-power fields; and (4) along with the extension of ECFC colonies, specific flat radial cells often appear at the periphery of colonies. After morphologic identification, two additional subcultures were performed to generate the $5 \times 10^{5}$ cells per wound needed for animal experiments.

\section{Animal model}

All animal experiments were conducted in accordance with the Guidelines for the Care and Use of Laboratory Animals (National Institutes of Health [NIH] publication No. 86-23) and were approved by the Soonchunhyang University Laboratory Animals Committee (approval No. SCHBCA2016-05). Male Institute of Cancer Research (ICR) mice at 10 weeks of age, weighing 40 to $50 \mathrm{~g}$ (Orientbio Inc., Seongnam, Korea) were used.

A total of 12 animals were anesthetized with peritoneal anesthesia using $0.008 \mathrm{~mL} / 10 \mathrm{~g}$ of Zoletil (Virbac Lab., Carros, France) and $0.002 \mathrm{~mL} / 10 \mathrm{~g}$ of Rompun (Bayer Co., Leverkusen, Germany). The hair was completely removed and the wound area sterilized with $7.5 \%$ povidone-iodine solution.

Two defects were made on each mouse, using a $0.8 \mathrm{~cm}$ diameter punch (Biopsy Punch; Kai Industries Co., Ltd., Gifu, Japan) on the dorsum, and a 0.5 -cm-thick donut-shaped silicon plate with a $9 \mathrm{~mm}$ diameter hole was placed on the area to repress wound contracture using Dermabond (Ethicon Inc., Somerville, NJ, USA) and a suture (Fig. 1).

\section{Scaffolds}

A $0.8 \mathrm{~cm}$ diameter, $0.5 \mathrm{~cm}$ thick cryogel manufactured by Soonchunhyang Institute of Medi-bio Science (SIMS) was used for cell transfer in all animal models.

\section{Materials}

Gelatin (type A, up to $300 \mathrm{~g}$ bloom from porcine skin), methacrylic anhydride, sodium 4-vinylbenzenesulfonate, N,N'methylenebisacrylamide, ammonium persulfate, and N,N,N,N'tetramethylethylenediamine were purchased from Sigma-Aldrich. 


\section{Synthesis of methacrylated gelatin}

Type A porcine skin gelatin was mixed at $10 \%(\mathrm{w} / \mathrm{v})$ into Dulbecco's phosphate-buffered saline (DPBS; Gibco) at $60^{\circ} \mathrm{C}$ and stirred until fully dissolved. Methacrylic anhydride was added until the target volume was reached at a rate of $0.5 \mathrm{~mL} / \mathrm{min}$ to the gelatin solution under stirred conditions at $50^{\circ} \mathrm{C}$ and was allowed to react for 1 hour. The fraction of lysine groups was modified by varying the amount of methacrylic anhydride present in the initial reaction mixture. Following a 5-fold dilution with additional warm $\left(40^{\circ} \mathrm{C}\right) \mathrm{DPBS}$ to stop the reaction,

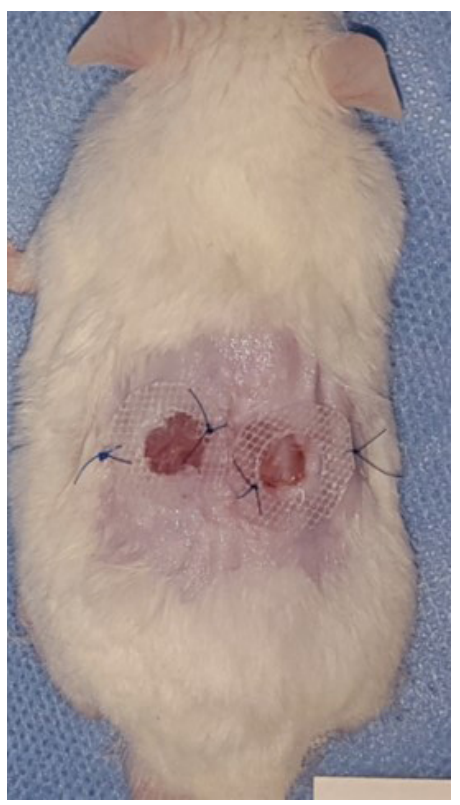

Fig. 1. Wound splinting model. A silicone plate was placed on the area after making a $0.8 \mathrm{~cm}$ wound in an Institute of Cancer Research mouse. the mixture was dialyzed against distilled water using 12-14 $\mathrm{kDa}$ cutoff dialysis tubing for 1 week at $40^{\circ} \mathrm{C}$ to remove salts and methacrylic acid. The solution was lyophilized for 1 week to generate a white porous foam and stored at $-80^{\circ} \mathrm{C}$ until further use $[7,8]$.

\section{Synthesis of cryogel}

Poly(ethylene glycol) diacrylate oligomers were dissolved in phosphate-buffered saline (PBS) to prepare a solution of $10 \%$. To this solution, the initiator-accelerator mixture $(0.5 \%$ of ammonium persulfate [APS] and either $0.05 \%$ or $0.1 \% \mathrm{w} / \mathrm{v}$ of tetramethylethylenediamine [TEMED]) was added at $4^{\circ} \mathrm{C}$, and the reaction mixture was polymerized at $14^{\circ} \mathrm{C}$ or $20^{\circ} \mathrm{C}$ for 20 hours. Two cooling rates were used to evaluate the effect of different degrees of supercooling and onset of the nucleation of ice crystals on cryogel formation and microstructure $[9,10]$.

Prior to the administration of the cells, the cryogel was sterilized with 70\% ethanol and washed with PBS. The cryogel was partially dried in a sterile environment 3 hours before the administration of the cells. Afterwards, the cell culture solution $(40 \mu \mathrm{L})$ was added dropwise to the cryogel, and cultured for about 2 hours to allow cells to penetrate the cryogel.

\section{CB-ECFC-like cell administration}

For one wound of each experimental animal, $40 \mu \mathrm{L}$ of $5 \times 10^{5}$ CB-ECFC-like cells cultured in EGM-2 medium (Lonza) was added to the cryogel, then adhered to the wound. On the control wounds, $40 \mu \mathrm{L}$ of EGM-2 (Lonza) alone was added to the cryogel, then adhered. All wounds were fixed with gauze and an adhesive bandage (Heka Haft; Van Heek Medical, Venray, the Netherlands), after dressing with Tegaderm (3M Health-

Table 1. Criteria to evaluate histological scores of wound healing

\begin{tabular}{|c|c|c|c|}
\hline Score & $\begin{array}{l}\text { Epidermal and dermal } \\
\text { regeneration }\end{array}$ & $\begin{array}{l}\text { Granulation tissue } \\
\text { thickness }\end{array}$ & Angiogenesis \\
\hline 1 & $\begin{array}{l}\text { Little epidermal and dermal } \\
\text { organization }\end{array}$ & Thin granulation layer & $\begin{array}{l}\text { Altered angiogenesis (one to two vessels per site) characterized by a high de- } \\
\text { gree of edema, hemorrhage, occasional congestion, and thrombosis }\end{array}$ \\
\hline 2 & $\begin{array}{l}\text { Moderate epidermal and } \\
\text { dermal organization }\end{array}$ & Moderate granulation layer & $\begin{array}{l}\text { Few newly formed capillary vessels (three to four per site), moderate degree of } \\
\text { edema and hemorrhage, occasional congestion and intravascular fibrin de- } \\
\text { position, absence of thrombosis }\end{array}$ \\
\hline 3 & $\begin{array}{l}\text { Complete remodeling of } \\
\text { epidermis and dermis }\end{array}$ & Thick granulation layer & $\begin{array}{l}\text { Newly formed capillary vessels (five to six per site), moderate degree of peri- } \\
\text { vascular and interstitial edema and congestion, absence of thrombosis and } \\
\text { hemorrhage }\end{array}$ \\
\hline 4 & & Very thick granulation layer & $\begin{array}{l}\text { Newly formed and well-structured capillary vessels (more than seven per site) } \\
\text { vertically disposed toward the epithelium and at the wound margins, slight } \\
\text { degree of perivascular edema }\end{array}$ \\
\hline
\end{tabular}

Reprinted from Galeano et al. Diabetes 2004;53:2509-17, with permission [11]. 
care, St. Paul, MN, USA).

\section{Measuring wound healing rate}

The size of the skin defect was measured under the same conditions on the 1st, 3rd, 7 th, and 14th days of the experiment, using a digital camera and a computer image analysis program (Image J; NIH, Bethesda, MD, USA). The rate of wound healing was calculated as ([size of the first wound-size of the measured wound $] /$ size of the first wound $) \times 100$.

\section{Histologic examination}

On the 3rd, 7th, and 14th days of experiment, the animals were sacrificed and the skin defect area, which included $4 \mathrm{~mm}$ of the normal skin around the wound, was excised to the panniculus carnosus layer. After the tissue was fixed in $10 \%$ formalin, the center of the wound was cut into a cross-section, embedded in a paraffin block, and cut into $5 \mu \mathrm{m}$ sections which were stained with hematoxylin and eosin ( $\mathrm{H} \& \mathrm{E})$. Cells were observed under an optical microscope at a magnification of $\times 100$, and the patterns of epithelialization, cell infiltration, amount of granulation tissues, and angiogenesis were measured and quantitated into histologic scores (Table 1) [11].

Table 2. Comparison of wound reduction rate

\begin{tabular}{lccc}
\hline Variable & $\begin{array}{c}\text { Cell }(+) \\
(n=3)\end{array}$ & $\begin{array}{c}\text { Cell }(-) \\
(n=3)\end{array}$ & P-value $^{\text {a) }}$ \\
\hline At 1 day & $10.9 \pm 8.0$ & $10.6 \pm 7.8$ & 0.827 \\
At 3 days & $31.0 \pm 13.6$ & $15.4 \pm 14.4$ & 0.076 \\
At 7 days & $50.9 \pm 18.9$ & $46.2 \pm 20.1$ & 0.465 \\
At 14 days & $89.9 \pm 6.1$ & $89.5 \pm 6.3$ & 0.754 \\
\hline
\end{tabular}

Values are presented as mean \pm SD. All unit of data is percent.

a)P-values were calculated by Student t-test.

Day 0

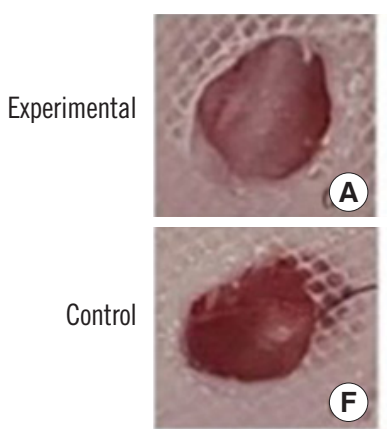

Day 1

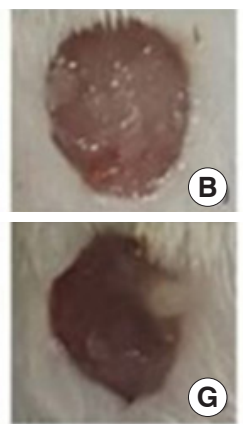

Day 3

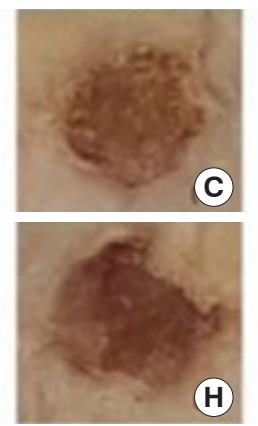

Immunohistochemistry

On the 3rd, 7th, and 14th days of the experiment, the tissues were immunohistochemically stained with anti-CD31 (1:100; Abcam, Cambridge, MA, USA) and anti-VEGF (1:250; Santa Cruz, Dallas, TX, USA).

Each result was captured by a digital camera (Olympus DP71; Olympus, Tokyo, Japan) attached to an optical microscope at a magnification of $\times 100$ and $\times 400$. The captured images were measured and compared with the degree of integrated optical density using the computerized image analysis program (Image J; NIH).

\section{Statistical analysis}

Statistical analysis was performed using SPSS for Windows

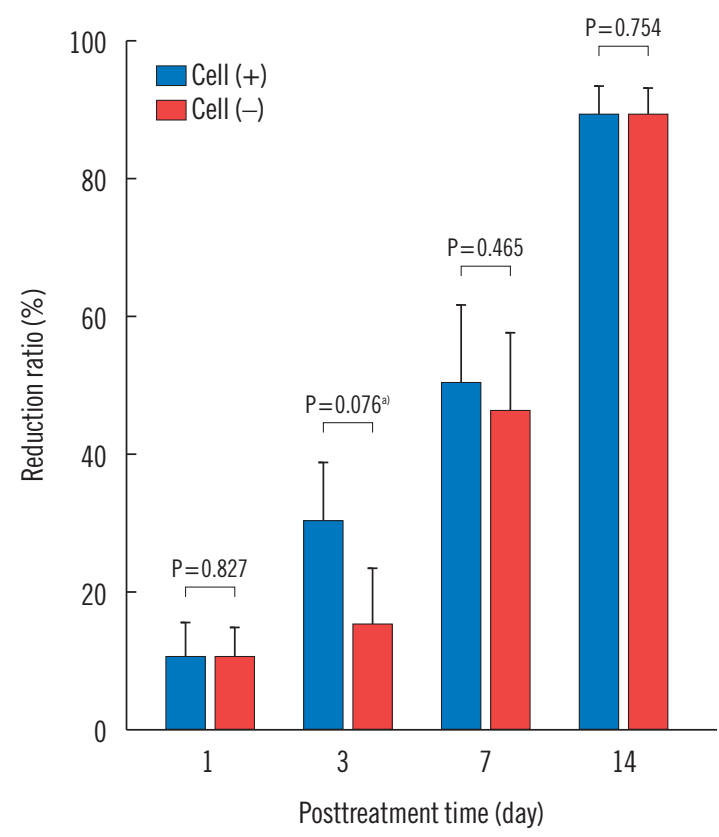

Fig. 2. Comparison of wound reduction rates (\%). ${ }^{a)} \mathrm{P}<0.05$.

Day 7

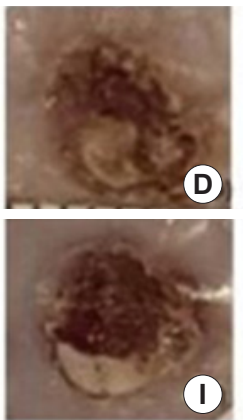

Day 14

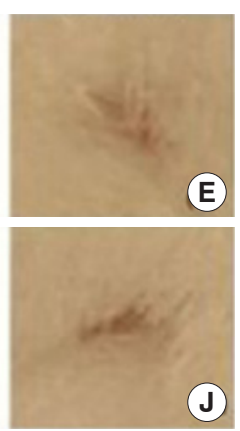

Fig. 3. Changes in wound size. (A-E) Experimental group and (F-J) control group. 
version 13.0 (SPSS Inc., Chicago, IL, USA). The validity of the variables was tested using a t-test. A P-value of less than 0.05 was considered significant.

\section{Results}

\section{Variation of wound size}

The wound reduction rates of the experimental side were $10.9 \% \pm 8.0 \%, 31.0 \% \pm 13.6 \%, 50.9 \% \pm 18.9 \%$, and $89.9 \% \pm$ $6.1 \%$, at days $1,3,7$, and 14 of the experiment period, respectively. The wound reduction rates of the control side were $10.6 \% \pm 7.8 \%, 15.4 \% \pm 14.4 \%, 46.2 \% \pm 20.1 \%$, and $89.5 \% \pm$ $6.3 \%$, at days $1,3,7$, and 14 of the experiment period, respectively. The wound reduction rates of the experimental side were higher than those of the control side at all measurement times. However, there was no statistical significance at any point (Table 2, Figs. 2 and 3).

\section{Histologic analysis}

The histologic scores of the wounds measured according to the

Table 3. Comparison of histologic scores

\begin{tabular}{lccc}
\hline Variable & $\begin{array}{c}\text { Cell }(+) \\
(n=4)\end{array}$ & $\begin{array}{c}\text { Cell }(-) \\
(n=4)\end{array}$ & P-value $^{\text {a) }}$ \\
\hline At 3 days & $5.8 \pm 1.3$ & $4.0 \pm 0.7$ & 0.037 \\
At 7 days & $7.4 \pm 1.1$ & $6.2 \pm 0.8$ & 0.101 \\
At 14 days & $9.2 \pm 1.8$ & $7.6 \pm 1.1$ & 0.104 \\
\hline
\end{tabular}

Values are presented as mean \pm SD.

a)P-values were calculated by Student t-test. criteria in Table 1 were $5.8 \pm 1.3,7.4 \pm 1.1$, and $9.2 \pm 1.8$ in the experimental side, and $4.0 \pm 0.7,6.2 \pm 0.8$, and $7.6 \pm 1.1$ in the control side on the 3rd, 7th, and 14th days of experiment, respectively. The scores of the experimental side were high on all days measured. On the 3rd day, the experimental side was significantly higher than the control side, but the differences on the 7th and 14th day were not statistically significant (Table 3 , Figs. 4 and 5).

$H \& E$ staining showed granulation tissue formation and neovascularization, accompanied by infiltration of inflammatory cells in the experimental side.

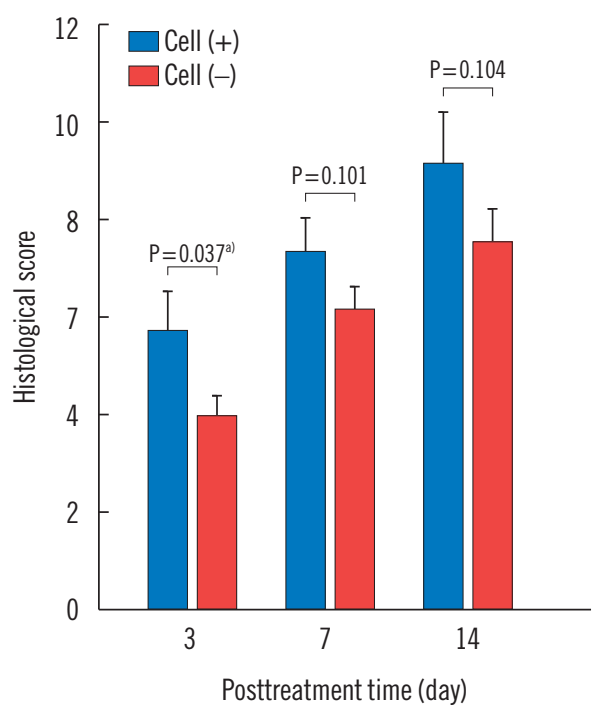

Fig. 4. Comparison of histologic scores. On the 3rd day, the experimental side was significantly higher than the control side. ${ }^{\text {a) }} \mathrm{P}<0.05$.

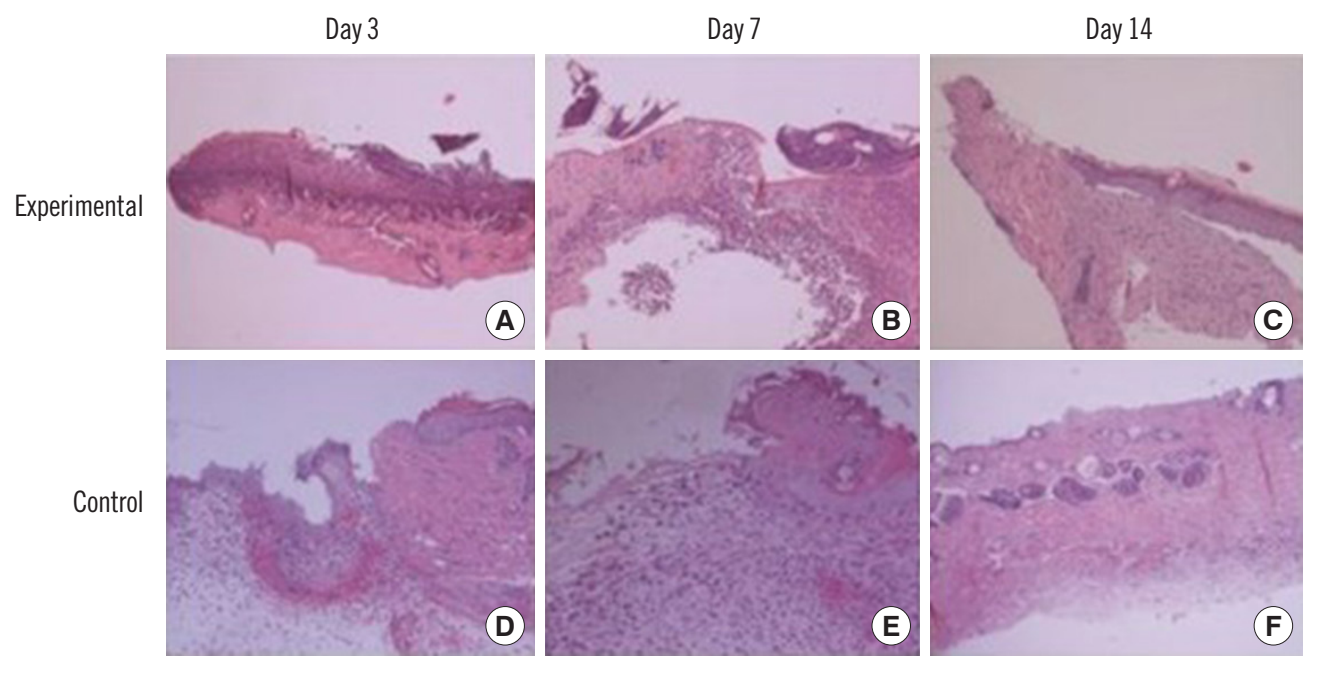

Fig. 5. Histologic examination of wound. (A-C) Experimental side $(H \& E, \times 100)$. (D-F) Control side $(H \& E, \times 300)$. 


\section{CD31 expression}

After intracellular CB-ECFC-like cells were injected into the wound, immunohistochemical staining for anti-CD31 was performed on the 3rd, 7th, and 14th days and quantified by the computerized image analysis program. Using this analysis, the optical density range is from 0 to 256 , and values closer to 0 indicate higher protein expression. The amount of CD31 was $130.8 \pm 19.3,135.1 \pm 16.0$, and $143.7 \pm 12.5$ in the experimental side, and $141.9 \pm 23.9,149.2 \pm 18.1$, and $152.0 \pm 12.3$ in the control side, on days 3,7 and 14 , respectively. There was no statistical significance in the experimental side at any time, compared to the control side (Table 4, Figs. 6 and 7).

\section{VEGF expression}

The amount of VEGF was $154.2 \pm 31.7,150.2 \pm 18.0$, and $143.5 \pm$ 22.2 in the experimental side, and $158.0 \pm 22.8,155.5 \pm 15.3$, and 151.8 \pm 19.2 in the control side on days 3, 7, and 14, respectively. There was no statistical significance in the experi-

Table 4. The degree of CD31 expression

\begin{tabular}{lccc}
\hline \multirow{2}{*}{ Variable } & \multicolumn{2}{c}{ CD31 optical density } & \\
\cline { 2 - 3 } & $\begin{array}{c}\text { Cell }(+) \\
(n=4)\end{array}$ & $\begin{array}{c}\text { Cell }(-) \\
(n=4)\end{array}$ & P-value ${ }^{\text {a) }}$ \\
\hline At 3 days & $130.8 \pm 19.3$ & $141.9 \pm 23.9$ & 0.248 \\
At 7 days & $135.1 \pm 16.0$ & $149.2 \pm 18.1$ & 0.142 \\
At 14 days & $143.7 \pm 12.5$ & $152.0 \pm 12.3$ & 0.221 \\
\hline
\end{tabular}

Values are presented as mean $\pm S D$.

a)P-values were calculated by Student t-test. mental side at any time, compared to the control side (Table 5, Figs. 8 and 9).

\section{Discussion}

There are recent studies on the clinical application of stem cells for wound healing. In wound healing, bone marrow stem cells are excellent for collagen synthesis and growth factor production [12]. Adipose stem cells have good angiogenesis affinity, promoting collagen formation and secreting various cytokines

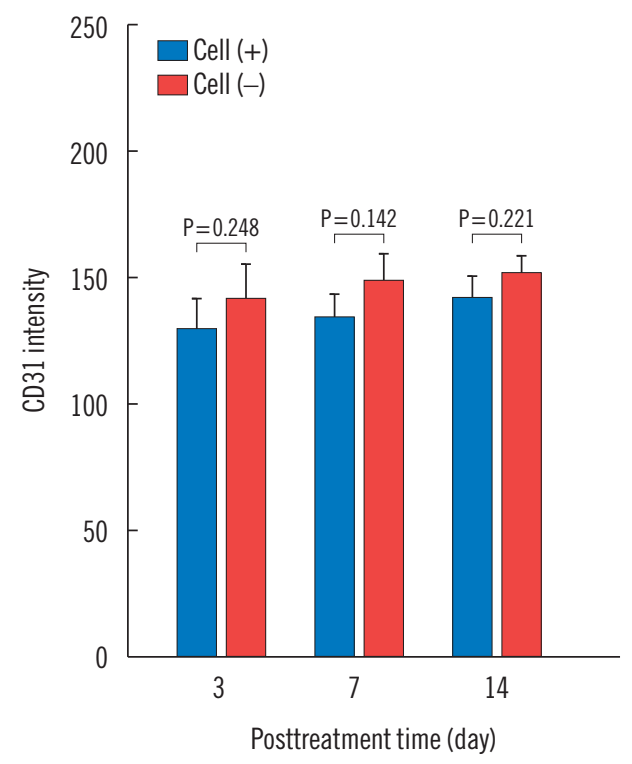

Fig. 6. Comparison of degrees of CD31 expression.

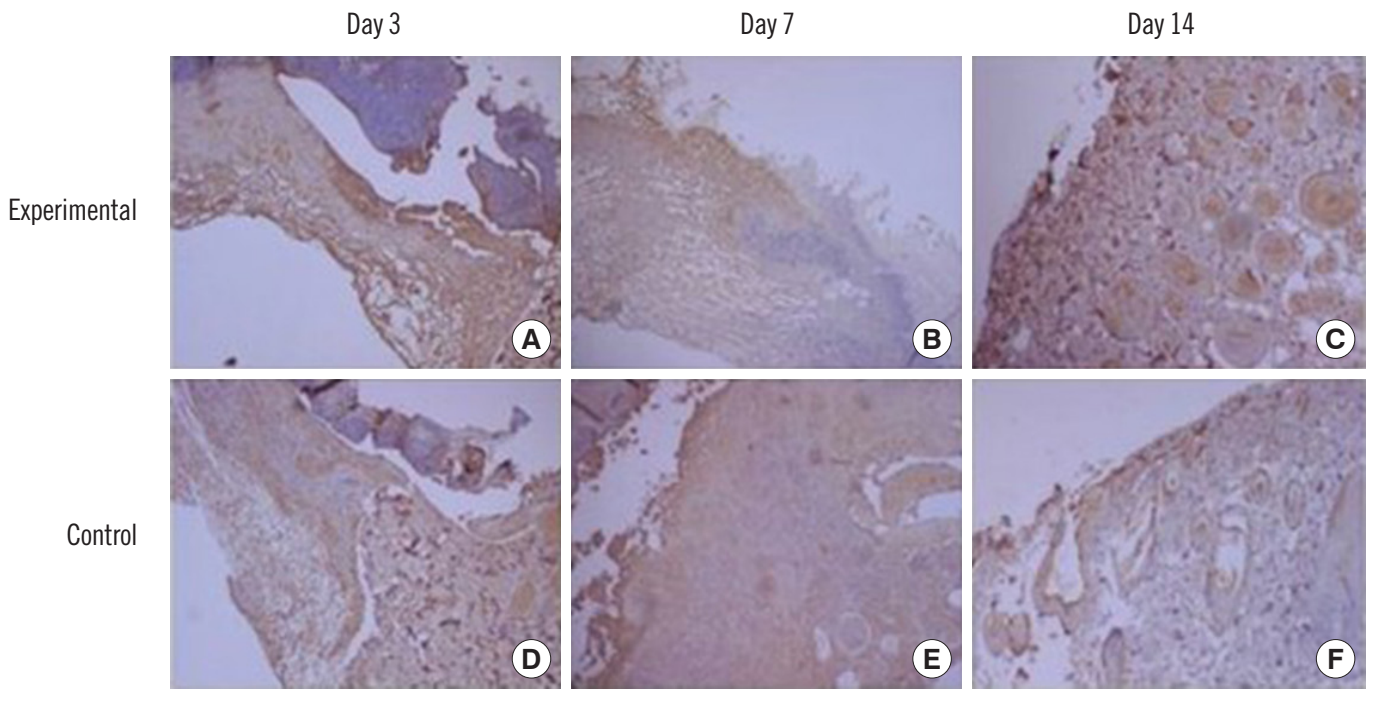

Fig. 7. CD31 staining findings. (A-C) Experimental side. (D-F) Control side. (A, B, D, E: x100; C, F: x300). 
that increase fibroblast recruitment $[13,14]$. However, it is difficult to obtain enough cells for the clinical application of adult stem cells, while the use of ESCs is fraught with ethical issues.

Consequently, hiPSCs have emerged as a promising new technology to overcome the limitations of other stem cells [15]. iPSCs can be produced by introducing a reprogramming factor into somatic cells using a viral vector, or by transferring the factors through the combined use of a protein transporter, followed by somatic cell de-differentiation. These hiPSCs can be produced through the differentiation process of a patient's adult cells, making patient-specific cell therapy possible [1]. Zhang et al. [16] induced the differentiation of pluripotent stem cells into myocardial cells, and compared their ability to differentiate with established human ESCs. Expression of myocardial cell markers similar to those of myocardial cells differentiated from human ESCs was confirmed in myocardial cells differentiated from iPSCs. In addition, the authors suc-

Table 5. The degree of VEGF expression

\begin{tabular}{lccc}
\hline & \multicolumn{2}{c}{ VEGF optical density } & \\
\cline { 2 - 3 } Variable & $\begin{array}{c}\text { Cell }(+) \\
(n=4)\end{array}$ & $\begin{array}{c}\text { Cell }(-) \\
(n=4)\end{array}$ & P-value \\
\hline At 3 days & $154.2 \pm 31.7$ & $158.0 \pm 22.8$ & 1.000 \\
At 7 days & $150.2 \pm 18.0$ & $155.5 \pm 15.3$ & 0.462 \\
At 14 days & $143.5 \pm 22.2$ & $151.8 \pm 19.2$ & 0.624 \\
\hline
\end{tabular}

Values are presented as mean \pm SD.

VEGF, vascular endothelial growth factor.

a)P-values were calculated by Student t-test. ceeded in the differentiation into motor neurons using somatic cells donated from other patients, which led to prospects that patient-tailored treatment using iPSCs could be possible [16]. Several studies have already reported that endothelial cells and endothelial progenitor cells from iPSCs are effective in ischemic animal models $[17,18]$. However, there are limitations to the use of iPSCs. Cancer expression and low production efficiency of desired cells because of the limited ability to differentiate have been reported [15]. Prasain et al. [19] showed

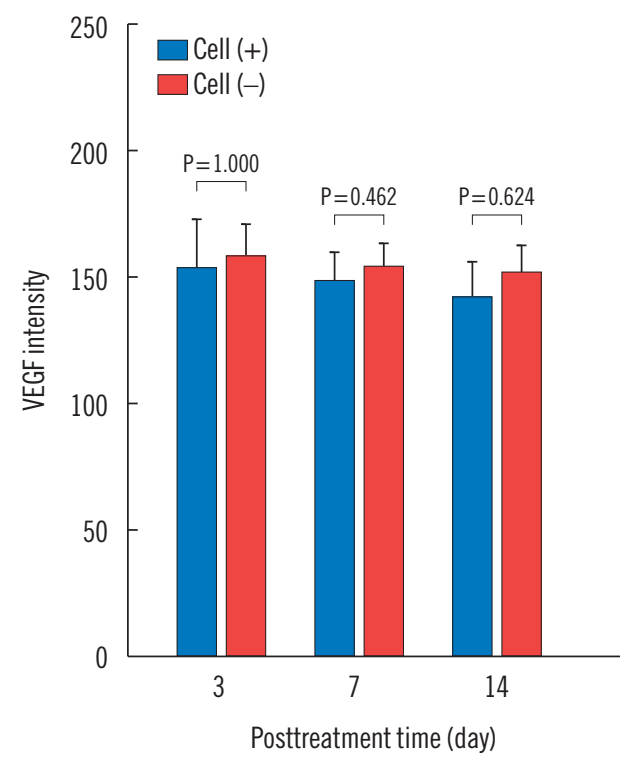

Fig. 8. Comparison of degrees of VEGF expression. VEGF, vascular endothelial growth factor.

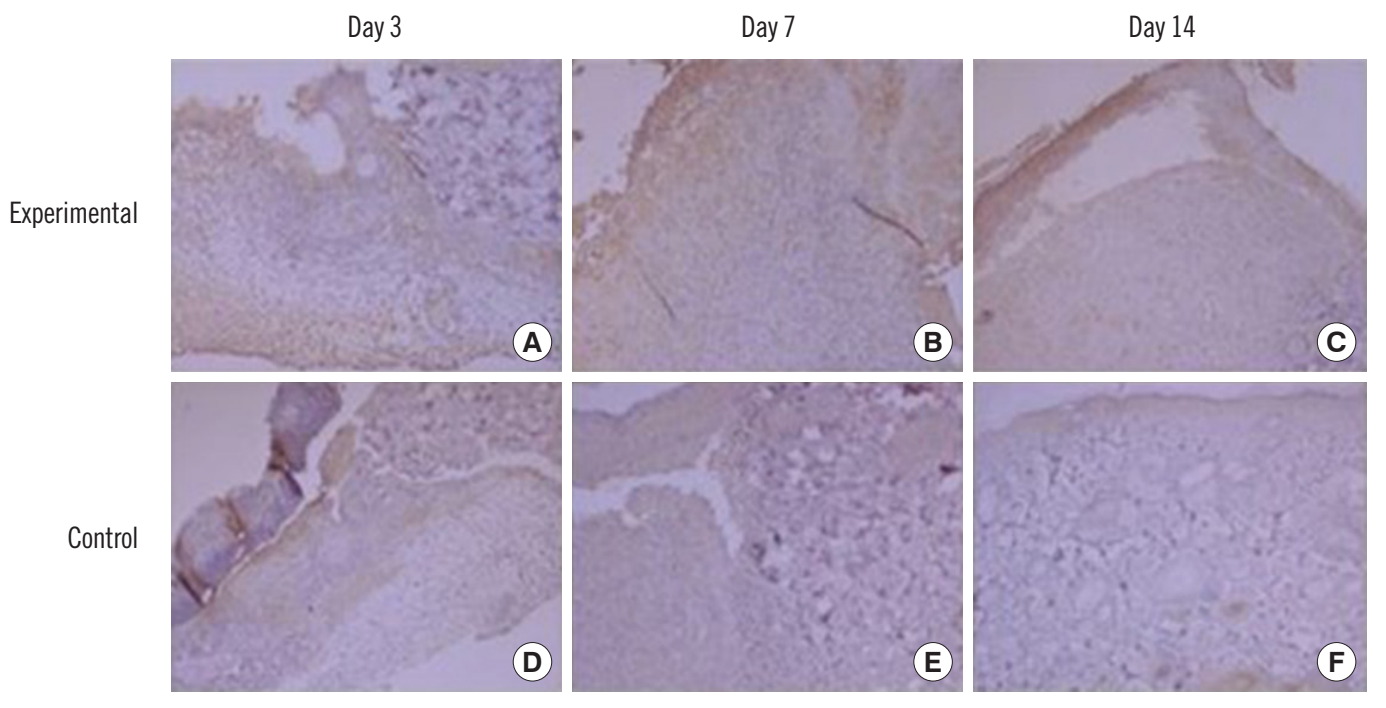

Fig. 9. VEGF staining findings ( $\times 300)$. (A-C) Experimental side. (D-F) Control side. VEGF, vascular endothelial growth factor. 
that the endothelial cell-forming cells derived from the iPSCs stably maintained the characteristics of the endothelial cells with high replication proliferation ability. In addition, it was confirmed that injection into the ischemic mouse model resulted in the formation of blood vessels and the recovery of blood flow in damaged tissues of the retina and limbs, but no teratoma. In this study, we evaluated the effects of neovascularization and granulation tissue formation in wound healing, using cells similar to CB-ECFCs, differentiated from iPSCs.

An example of recent interest in such cell therapy is the use of scaffolds to facilitate cell delivery. Rapid vascularization is essential because transplanted cells and scaffolds in the body survive by supplying nutrients and oxygen through the host's blood vessels. Particularly, for long-term survival of cells in a bulky supporter made in a three-dimensional shape, it is necessary to vascularize the support so that sufficient oxygen and nutrients can be supplied. Hydrogel is one of the scaffolds widely used in cell therapy because of its high biocompatibility, hydrophilicity and porosity, which facilitate cell survival and permeation of cell-mediating substances. Recent developments in freezing gelation technology have enabled hydrogels to be fabricated with a finely interconnected porous structure, called cryogel. The fabricated cryogel has excellent physical properties and expandability. Unlike hydrogels, which are composed of closed structures, the cryogels are interconnected. They also have the advantage of being able to withstand larger deformation and faster re-absorption when immersed in aqueous solution. Recent studies have exploited these advantages to use cryogel for cell therapy research. Kathuria et al. [20] reported the adhesion and proliferation of fibroblasts and the enhancement of extracellular matrix secretion using chitosan-gelatin cryogel.

In this experiment, we used methacrylated gelati (GelMA)based cryogel, which is a porous network of GelMA made by freezing gelation. GelMA, formed by hydrolyzing collagen, facilitates cell attachment and has good bioactivity [21]. This GelMA-co-poly(styrene sulfonate) scaffold facilitates injection of the cell-containing solution and allows the cell solution to be rapidly absorbed and easily transported without damage.

The iPSCs used in this experiment are similar to CB-ECFCs and have excellent characteristics of differentiation and angiogenesis [18]. Our study suggests that iPSCs also promote angiogenesis and granulation tissue formation in the wound healing models of mice, and as a result, they are effective in wound healing.

Important factors in wound healing are wound contraction and angiogenesis [18]. The main mechanism of wound healing in the human body is re-epithelialization and granulation tissue formation [22]. However, the main principal of wound healing of rodents, including rats, is wound contraction. Therefore, in this study, a wound model based on a silicon plate was used to limit the wound contraction. Angiogenesis is manifested by the action of endothelial cells and various cytokines, such as FGF and VEGF, and new angiogenesis is observed in the proliferative phase during the wound healing process, at approximately 2 to 3 days [23]. In the wound healing results of this experiment, there was no significant difference between the experimental side and the control side on the 1st day, but there was a noticeable difference on the 3rd day, and all wounds were completely healed by the 14th day. The histologic score of the experimental side was also significantly higher than in the control side $(\mathrm{P}<0.05)$ on the 3 rd day. From the 3rd day, the wound healing rate was higher in the experimental side, suggesting endothelial cell proliferation and neovascularization by CB-ECFC-like cells. The expression of CD 31 was higher in the four mice injected with cells than those without injections on days 3, 7, and 14. But there was no statistically significant difference, because the small number of mice used in the experiment made it difficult to obtain statistical significance. In addition, VEGF, which is known to play a major role in the formation of new blood vessels, was measured. In the experimental side, the expression of VEGF was increased compared to that of the control side, and the number of new blood vessels also increased, shown by H\&E staining. The granulation tissue composed of fibroblasts, capillaries, and immature cells was formed during the wound healing process, and both the number of cells and number of new blood vessels in the experimental side increased. Thus, the developed granulation tissue formation in the experimental side affected the wound healing. Neovascularization and granulation formation were accelerated on day 3 and day 7 , but both sides were healed on day 14 . This is because the size of the wounds used in the experiment was as small as $0.8 \mathrm{~cm}$, enabling quick healing of the wounds.

The limitation of this study was the relatively small size $(0.8$ $\mathrm{cm}$ ) of the wounds; the difference between the two sides was small when the wound was completely healed on the 14th day. However, on the 3rd and 7th days of experiment, the rate of wound healing, granulation tissue formation, and angiogenesis were higher in the experimental side. In addition, the number of mice in the experimental group was small, making it difficult to obtain statistical significance. Our results suggest 
that further studies should be carried out increasing the size of the wounds and using a larger number of animals.

A full-thickness skin defect was created using a $0.8 \mathrm{~cm}$ punch in 10-week-old mice (ICR), CB-ECFCs-like cells differentiated from $5 \times 10^{5}$ hiPSCs were injected, and GelMA cryogel was used as a scaffold. The expression levels of CD31 and VEGF were analyzed, and H\&E staining, and molecular biology also analyzed. The results were as follows.

On day 3 after the administration of the cells, the wound healing rate was increased $(\mathrm{P}<0.1)$, and the histological score was significantly higher $(\mathrm{P}<0.05)$ in the experimental side, compared to controls. On the $3 \mathrm{rd}$, 7th, and 14th days after the administration of the cells, neovascularization and granulation formation were increased, compared to the control side. The expression levels of CD31 and VEGF by immunostaining were not statistically significant $(\mathrm{P}>0.05)$, but they were increased at all time points measured, compared to the control side.

In conclusion, it was confirmed that umbilical CB-ECFCslike cells differentiated from hiPSCs promote neovascularization and granulation tissue formation in a wound healing model that used $0.8 \mathrm{~cm}$ full-thickness defects in mice.

\section{Conflict of interest}

This work was supported by the Soonchunhyang University Research Fund. Otherwise, no potential conflicts of interest relevant to this article are reported.

\section{ORCID iDs}

Sang Hun Kim

Jeoung Hyun Nam

Man Ryul Lee

Yongsung Hwang

Eun Soo Park

\section{References}

1. Yamanaka S. Strategies and new developments in the generation of patient-specific pluripotent stem cells. Cell Stem Cell 2007;1:39-49.

2. Lau K, Paus R, Tiede S, et al. Exploring the role of stem cells in cutaneous wound healing. Exp Dermatol 2009;18: 921-33.

3. Li S, Li Q. A promising approach to iPSC-based cell therapy for diabetic wound treatment: direct lineage reprogram- ming. Mol Cell Endocrinol 2014;393:8-15.

4. Galiano RD, Michaels J 5th, Dobryansky M, et al. Quantitative and reproducible murine model of excisional wound healing. Wound Repair Regen 2004;12:485-92.

5. Yu J, Hu K, Smuga-Otto K, et al. Human induced pluripotent stem cells free of vector and transgene sequences. Science 2009;324:797-801.

6. Yu S, Li Z, Zhang W, et al. Isolation and characterization of endothelial colony-forming cells from mononuclear cells of rat bone marrow. Exp Cell Res 2018;370:116-26.

7. Nichol JW, Koshy ST, Bae H, et al. Cell-laden microengineered gelatin methacrylate hydrogels. Biomaterials 2010; 31:5536-44.

8. Hutson CB, Nichol JW, Aubin H, et al. Synthesis and characterization of tunable poly(ethylene glycol): gelatin methacrylate composite hydrogels. Tissue Eng Part A 2011;17: 1713-23.

9. Hwang Y, Sangaj N, Varghese S. Interconnected macroporous poly(ethylene glycol) cryogels as a cell scaffold for cartilage tissue engineering. Tissue Eng Part A 2010;16: 3033-41.

10. Hwang Y, Zhang C, Varghese S. Poly(ethylene glycol) cryogels as potential cell scaffolds: effect of polymerization conditions on cryogel microstructure and properties. J Mater Chem 2010;20:345-51.

11. Galeano M, Altavilla D, Cucinotta D, et al. Recombinant human erythropoietin stimulates angiogenesis and wound healing in the genetically diabetic mouse. Diabetes 2004;53: 2509-17.

12. Kim KS. Book review: advances in wound repair. Arch Plast Surg 2013;40:639-40.

13. Cherubino M, Rubin JP, Miljkovic N, et al. Adipose-derived stem cells for wound healing applications. Ann Plast Surg 2011;66:210-5.

14. Yoon JW, Lim JS, Kim JN, et al. Effect of allogenic adiposederived stromal cells on wound healing in $\mathrm{BALB} / \mathrm{c}$ mice. J Korean Soc Plast Reconstr Surg 2010;37:323-8.

15. Takahashi K, Tanabe K, Ohnuki M, et al. Induction of pluripotent stem cells from adult human fibroblasts by defined factors. Cell 2007;131:861-72.

16. Zhang J, Wilson GF, Soerens AG, et al. Functional cardiomyocytes derived from human induced pluripotent stem cells. Circ Res 2009;104:e30-41.

17. Kim KL, Song SH, Choi KS, et al. Cooperation of endothelial and smooth muscle cells derived from human induced pluripotent stem cells enhances neovascularization in der- 
mal wounds. Tissue Eng Part A 2013;19:2478-85.

18. Rufaihah AJ, Huang NF, Jame S, et al. Endothelial cells derived from human iPSCS increase capillary density and improve perfusion in a mouse model of peripheral arterial disease. Arterioscler Thromb Vasc Biol 2011;31:e72-9.

19. Prasain N, Lee MR, Vemula S, et al. Differentiation of human pluripotent stem cells to cells similar to cord-blood endothelial colony-forming cells. Nat Biotechnol 2014;32: 1151-7.

20. Kathuria N, Tripathi A, Kar KK, et al. Synthesis and characterization of elastic and macroporous chitosan-gelatin cryogels for tissue engineering. Acta Biomater 2009;5:40618.

21. Hu X, Ma L, Wang C, et al. Gelatin hydrogel prepared by photo-initiated polymerization and loaded with TGF-beta1 for cartilage tissue engineering. Macromol Biosci 2009; 9:1194-201.

22. Davidson JM. Animal models for wound repair. Arch Dermatol Res 1998;290 Suppl:S1-11.

23. Gillitzer R, Goebeler M. Chemokines in cutaneous wound healing. J Leukoc Biol 2001;69:513-21. 